\title{
Horizontal Natural Product Transfer: A so far Unconsidered Source of Contamination of Plant-Derived Commodities
}

\author{
Dirk Selmar*, Alzahraa Radwan and Melanie Nowak \\ Institute for Plant Biology, TU Braunschweig, Mendelssohnstr, 4, 38106 Braunschweig, Germany
}

\begin{abstract}
It is well known that allelochemicals or xenobiotics such as systemic pesticides, veterinary remedies etc., are taken up by plants from the soil. However, information is lacking as to whether or not this uptake of organic compounds represents an isolated, singular event, or if it is a general phenomenon. Just recently, it was shown that nicotine, leached out from rotting tobacco into the soil, is taken up in the same manner. The question arises if other natural products, such as alkaloids, phenols or terpenes might be imported in the same manner. This may be particularly relevant for all the substances that are leached from decomposing plants. In this paper, the novel concept of "horizontal transfer of natural substances" based on the uptake of alkaloids derived from decaying plant materials is illustrated: after plant death, the soluble substances - including all natural products - are leached out from the decompartmented plant remains into the soil and are taken up by other plants. Related nutritional aspects as well as the significance of this phenomenon for our understanding of allelopathy are addressed.
\end{abstract}

Keywords: Horizontal transfer; Natural products; Contamination; Allelopathy

\section{Uptake of Functional Substances}

It is well established that systemic herbicides and fungicides, as well as other xenobiotics, e.g., veterinary medicines, are taken up by plant roots from the soil and translocated into the shoots [1,2]. Moreover, various phytotoxic compounds liberated from decomposing plant material are known to be imported into other plants [3]. Furthermore, salicylic acid, responsible for systemic acquired resistance, could be taken up by plants from the soil $[4,5]$. In contrast to the uptake of mineral nutrients, which is facilitated by certain transport proteins [6], no information is presently available about whether corresponding transporters for organic molecules exist. It seems plausible that they diffuse passively through root membranes due to the largely hydrophobic character of the molecules [7-9].

Up to date, information was lacking concerning whether or not such uptake of organic compounds represents isolated, singular events or if it corresponds to a more general principle. Yet, just recently it has been demonstrated that nicotine derived from dried tobacco plant material, is taken up by peppermint plants. Obviously, nicotine is leached out from plant remains into the soil and is subsequently taken up by other plants.

Accordingly, it could be assumed that also other organic natural products may be imported in the same manner. In particular, this may be important for substances that are leached from decomposing plants. Indeed, a corresponding transfer of substances is well known and described by allelopathy [10]. However, based on the actual understanding of allelopathy, only the transfer of so-called "functional substances" had been considered; i.e., which are known to inhibit the growth or germination of other plants. Yet, the occurrence of an increasing number of contaminations of plant-derived commodities by various natural products (see below) points to a far more general feature. Thus, in forthcoming studies it has to be elucidated whether or not such movement of compounds from one plant to another through the soil, which is here denoted as "horizontal natural product transfer", represents a far more universal process.

\section{Horizontal Natural Product Transfer as Source of Contaminations}

Because of toxicological concerns related to the use of nicotinecontaining pesticides a ban of these substances was made by the EU [11]. As a result plant-derived commodities were subsequently investigated in more detail. Surprisingly, the maximum residue level for nicotine $\left(0.01 \mathrm{mg} \mathrm{kg}^{-1}\right.$ d.w. $=10 \mu \mathrm{g} \mathrm{kg}^{-1}$ d.w. $)$ was frequently and drastically exceeded in many samples, e.g., in products of peppermint, chamomile, and oregano. The most striking examples published by the European Food Safety Authority [12] are presented in Table 1. First, an assumption was made that these nicotine levels were due to prolonged and illegal usage of nicotine-containing insecticides. However, this putative cause was rapidly disproved, because nicotine was also found in a number of plant-derived commodities that were produced under controlled and carefully monitored growth conditions without utilization of any insecticides. Consequently, there must be another origin for the nicotine contamination observed. It was then assumed that cigarette smoking and nicotine derived from smoking tobacco, respectively, might be the source. Indeed, mulching experiments with cigarette tobacco revealed that nicotine originated from tobacco is readily taken up by peppermint plants [13]. After uptake by the roots, the alkaloid is translocated into the shoots. Meanwhile, we were able to demonstrate that this process also takes place in other species, e.g., camomile and strawberries. Accordingly, the reported nicotine contaminations could at least partially be due to the uptake of nicotine from residues of cigarettes discarded in the fields [13]. Yet, up to now

*Corresponding author: Dirk Selmar, Institute for Plant Biology, TU Braunschweig Mendelssohnstr, 4, 38106 Braunschweig, Germany, Tel: +49(0)531-391-5881; E-mail: d.selmar@tu-bs.de

Received March 07, 2015; Accepted April 15, 2015; Published April 20, 2015

Citation: Selmar D, Radwan A, Nowak M (2015) Horizontal Natural Product Transfer: A so far Unconsidered Source of Contamination of Plant-Derived Commodities. J Environ Anal Toxicol 5: 287. doi:10.4172/2161-0525.1000287

Copyright: $\odot 2015$ Selmar D et al. This is an open-access article distributed under the terms of the Creative Commons Attribution License, which permits unrestricted use, distribution, and reproduction in any medium, provided the original author and source are credited. 


\begin{tabular}{|c|c|c|c|}
\hline Commodity & $\begin{array}{l}\text { Maximum value } \\
\text { of contamination } \\
\qquad(\mu \mathrm{g} / \mathrm{g} \text { d.w.) }\end{array}$ & $\begin{array}{l}\text { Samples } \\
\text { containing nicotine }\end{array}$ & $\begin{array}{l}\text { Number of } \\
\text { samples } \\
\text { analyzed }\end{array}$ \\
\hline Camomile flowers & 4.08 & $64 \%$ & 160 \\
\hline Linden flowers & 1.08 & $98 \%$ & 43 \\
\hline Rose hips & 0.88 & $81 \%$ & 81 \\
\hline Black tea & 0.87 & $82 \%$ & 235 \\
\hline Green tea & 0.44 & $84 \%$ & 93 \\
\hline Sage leaves & 0.35 & $100 \%$ & 22 \\
\hline Blackberry leaves & 0.28 & $89 \%$ & 45 \\
\hline Mate leaves & 0.21 & $100 \%$ & 5 \\
\hline Peppermint leaves & 0.11 & $58 \%$ & 118 \\
\hline
\end{tabular}

Table 1: Nicotine contamination in plant-derived commodities based on the data published by the EFSA [12,13].

no valid data on the actual exposure of soils by tobaccos products, such as discarded residues of cigarettes, are available.

Translocation of nicotine from roots into the leaves could be performed by either xylem or phloem transport. In the case of xylem transport, nicotine would be entrained passively by transpiration flow. In contrast, phloem-related translocation requires an active source-sink-allocation. Comparison of nicotine concentrations in young, middle aged and older leaves clearly revealed that the highest alkaloid concentrations were present in older leaves, i.e., the leaf tissues that exhibit the greatest transpirational surface. In contrast, smaller young leaves, representing physiological sinks, had far lower nicotine concentrations [13]. From this, it was deduced that nicotine is translocated via the xylem, driven by transpirational flow. Further analyses showed much of the nicotine is present in guttation droplets of the "acceptor plant", which also confirms the postulated xylem transport. These findings are in accordance to Weidner et al. [14], who also found nicotine in the xylem sap, when nicotine was fed to a hydroponic system of Epipremnum (Araceae).

Analogously to nicotine, contamination by pyrrolizidine alkaloids in plant-derived commodities also has been detected [15]. Further, tropane alkaloids are also reported to occur in a number of foods and feeds [16]. In these cases, however, the main source of the alkaloids seems to be due to impurities of certain pyrrolizidine or tropane alkaloids containing plants (e.g., Senecio spp, or Datura spp) $[1,16]$ in the plant-derived commodities. Nonetheless, uptake of these alkaloids from the soil may contribute to these contamination problems. This hypothesis has recently been investigated by mulching peppermint and camomile plants with dried Senecio leaves. The initial results indicate uptake of pyrrolizidine alkaloids from the soil. Hence, further analyses using various classes of alkaloids and other natural products such as phenols and terpenes need to be carried out in order to clarify the extent and prevalence of putative horizontal transfer of natural compounds. First experimental data from our lab reveal that also coptisine, a benzylisoquinoline alkaloid from Chelidonium majus is taken up by peppermint plants, too (data not shown).

In addition to the toxicological aspects due to the uptake of nicotine [17] and pyrrolizidine alkaloids [18] - which had been leached out from decomposing plants - the occurrence of such horizontal natural product transfer may also influence our general understanding of allelopathy. Whereas up to now allelopathy considers only a putative transfer of any functional substances released by various plants [10], we have to be aware that such events might occur far more frequently. This means that e.g., an alkaloid, derived from one plant, can be translocated

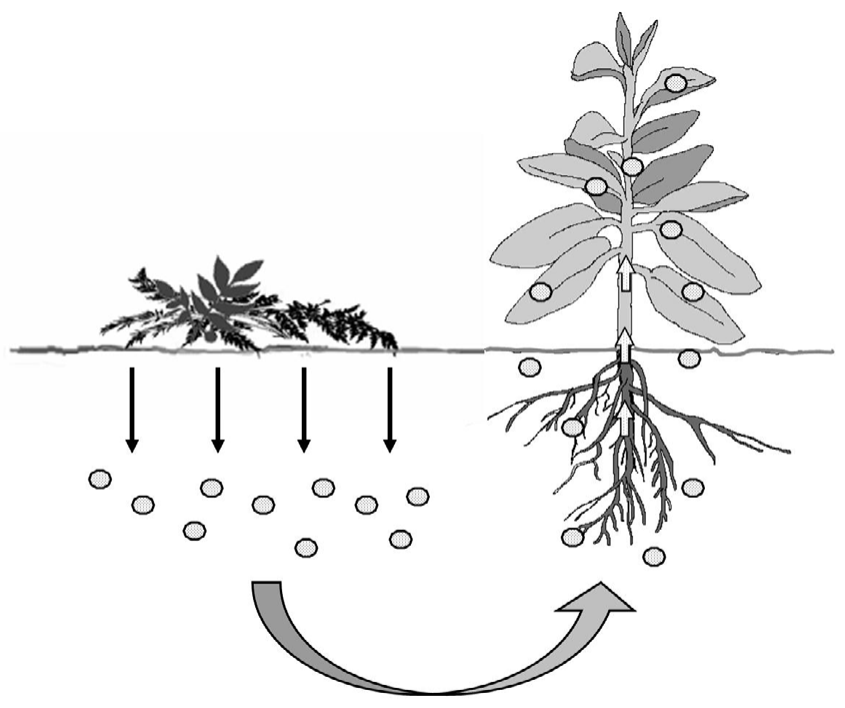

Figure 1: Horizontal transfer of natural products. 
Citation: Selmar D, Radwan A, Nowak M (2015) Horizontal Natural Product Transfer: A so far Unconsidered Source of Contamination of Plant-Derived Commodities. J Environ Anal Toxicol 5: 287. doi:10.4172/2161-0525.1000287

via the soil into another plant species, even though, if there will be no direct functional relevance.

The occurrence of such horizontal transfer of natural products by translocation of various compounds into other plant species may also provide an explanation for the hitherto unexplained processes related to beneficial effects of crop rotations or the co-cultivation of certain vegetables (Figure 1).

\section{Acknowledgement}

The authors wish to thank Prof. Dr. Dave Seigler, University of Illinois, for critical reading of the manuscript, helpful suggestions and fruitful discussions.

\section{References}

1. Boxal AB, Johnson P, Smith EJ, Sinclair CJ, Stutt E, et al. (2006) Uptake of veterinary medicines from soils into plants. J Agric Food Chem 54: 2288-2297.

2. Trapp S, Legind CN (2011) Uptake of organic contaminants from soil into vegetables and fruits. Dealing with Contaminated Sites, Springer 369-408.

3. Chou CH, Patrick ZA (1976) Identification and phytotoxic activity of compounds produced during decomposition of corn and rye residues in soil. $J$ Chem Ecol 2: 369-387.

4. Manthe B, Schulz M, Schnabl H (1992) Effects of salicylic acid on growth and stomatal movements of Vicia faba L.: Evidence for salicylic acid metabolization. J Chem Ecol 18: 1525-1539.

5. De Meyer G, Capieau K, Audenaert K, Buchala A, Métraux JP, et al. (1999) Nanogram amounts of salicylic acid produced by the rhizobacterium Pseudomonas aeruginosa 7NSK2 activate the systemic acquired resistance pathway in bean. Mol Plant Microbe Interact 12: 450-458.

6. Chrispeels MJ, Crawford NM, Schroeder JI (1999) Proteins for transport of water and mineral nutrients across the membranes of plant cells. Plant Cell 11: 661-676.
7. Inoue J, Chamberlain K, Bromilow RH (1998) Physicochemical factors affecting the uptake by roots and translocation to shoots of amine bases in barley. Pestic Sci 54: 8-21.

8. Nwoko CO (2010) Trends in phytoremediation of toxic elemental and organic pollutants. Afr J Biotechnol 9: 6010-6016.

9. Sibout R, Höfte $H(2012)$ Plant cell biology: the $A B C$ of monolignol transport Curr Biol 22: R533-535.

10. Seigler DS (2006) Basic pathways for the origin of allelopathic compounds. In: Allelopathy - A Physiological Process with Ecological Implications Reigosa MJ, Pedrol N, González L (eds) Springer, Heidelberg 11-61.

11. Commission Decision (2009) Concerning the non-inclusion of nicotine in annex I to Council Directive 91/414/EEC and the withdrawal of authorisations for plant protection products containing that substance. Official Journal of the European Union L.

12. European Food Safety Authority-EFSA (2011) Setting of temporary MRLs for nicotine in tea, herbal infusions, spices, rose hips and fresh herbs. EFSA Journal 9: 2098

13. Selmar D, Engelhardt UH, Hänsel S, Thräne C, Nowak M, et al. (2015) Nicotine uptake by peppermint plants as a possible source of nicotine in plant-derived products. Agron Sustain Develop.

14. Weidner M, Silva JAT (2006) Potential and limitations of ornamental plants for indoor-air purification. In: Floriculture, Ornamental and Plant Biotechnology Advances and Topical Issues, Silva JAT (Eds) Global Science Books, Ikenobe 54-63.

15. European Food Safety Authority - EFSA (2011) Scientific Opinion: Scientific opinion on pyrrolizidine alkaloids in food and feed EFSA J 9: 2406.

16. European Food Safety Authority - EFSA (2013) Scientific Opinion: Scientific opinion on tropane alkaloids in food and feed. EFSA J 11: 3386.

17. Karaconji IB (2005) Facts about nicotine toxicity. Arh Hig Rada Toksikol 56 363-371.

18. Wiedenfeld $\mathrm{H}$, Edgar $\mathrm{J}$ (2011) Toxicity of pyrrolizidine alkaloids to humans and ruminants. Phytochem Rev 10: 137-151. 